Psychiatric Bulletin

\title{
Integration into the working world
}

\author{
Bob Grove, Assistant Director, The Richmond Fellowship for Community Mental \\ Health, 8 Addison Road, Kensington, London W14
}

The Richmond Fellowship has for almost 30 years been a leading mental health organisation delivering half way house care and rehabilitation to people needing to overcome the secondary social effects of mental breakdown. It has developed the half way house therapeutic community principally as a short term institution with a programme which stresses social relations and self management, and as such has been beneficial to many thousands of people who have quickly re-established themselves into their families and communities.

For the past decade and more, however, the rapid decanting of the chronic population of the large mental hospitals has combined with rising unemployment and the welfare benefit dependency trap to focus attention on the long-term housing needs of the chronically mentally ill and the extreme difficulty experienced by people with mental health problems in obtaining and sustaining any kind of employment.

The Fellowship has identified two major and distinct employment needs for residents in its expanding range of services. Firstly, the need for younger people who have suffered acute breakdown to be introduced or reintroduced into work in ways which avoid the catastrophic loss of confidence which failure to hold down a job can produce. Secondly, for the residents in our long-stay houses there is a need for a dignified and productive alternative to hobby based day care, which enables them to feel a part of the working community albeit in a way which makes allowances for periods of low productivity or mental deterioration. The need that is common to both groups is the opportunity to discover or rediscover skills and areas of competence and to learn or relearn how to manage the social relationships of the workplace.

Four years ago we were fortunate to be invited to take over the Castle Project in Cambridge which included a small workshop set up as a Manpower Services Commission (MSC) Community Programme scheme for young people (mostly from Fulbourn Young People's Unit) who needed a period in which their confidence could be rebuilt prior to attempting

Paper delivered to the Spring Quarterly Meeting of the Royal College of Psychiatrists at Robinson College Cambridge, 12 April 1988. outside employment. This project has now doubled in size and expanded its range of products and services from furniture restoration to the manufacture of toys and kitchen ware, hot foil printing, contract packaging, quality chair caning and rush seating, and providing the senior citizens of Cambridge with kindling wood.

Three years ago another opportunity presented itself when we were approached by social service departments and the health authorities in Sutton and Merton, who were concerned that, with the closure of Banstead Hospital, at least 40 residents from the Boroughs who used the Industrial Therapy Unit there would have no suitable day care provision. A package of funding using Joint Finance was quickly assembled and with considerable help and sponsorship from local and national industry and commerce, notably Messrs Marks \& Spencer, a 70 place workshop now known as Unit Five was designed and commisioned in a period of nine months.

The lessons learned from the past few years have been many. In this paper I shall deal with three main issues.

\section{The working environment}

The first point I wish to make concerns the location and internal facilities of the workshops. For reasons of economy and convenience, a depressingly large proportion of the few workschemes which have opened in the past few years as part of the Care in the Community initiative have been situated in discarded institutional buildings which were designed for another purpose.

Hence we see workshops on disused hospital sites and in converted wards, sometimes with no vehicular access. We see workshops in former local government office blocks, in disused schools and even in parts of disused churches. "Well what is wrong with that?" people ask. "Is it not simply a sensible use of available resources - the sort of opportunism that you are encouraging when talking about obtaining machinery and materials for your own products?"

My answer is that if using a building for a purpose for which it was not designed is an economy in the short term, in the long term it is a false economy both commercially and therapeutically. 
The Castle Project Workshop comprises two small starter units on a mini industrial estate about a mile from the city centre. Unit Five is a large unit $11,000 \mathrm{sq} f \mathrm{ft}$ an industrial area in South London.

The advantages are simply stated:

(a) Commercially, an undivided rectangular industrial unit is flexible, easily supervised and equipped with the basic requirements to instal machinery, and collect and deliver goods. It also stands among several or even scores of other similar businesses which together form a network of reciprocal relationships and which generate service needs frequently ideally suited to the capacities of our workforce. Hence we have neighbours who lend us vehicles and ladders and who also give us workpacking and assembly work, printing anything which is unskilled and labour intensive. Their workforce are also customers for our sales of our products.

(b) Therapeutically, there are also huge benefits. Contrary to our experience of setting up residential projects in residential areas, initial neighbourly suspicion or even hostility is absent from the development of a workshop in an industrial area. What is more, our workers arrive and depart alongside all the other people on the estate, eliminating stigma and giving a dignity which an isolated or inappropriately located unit simply could not produce.

Inside the workshops we have tried in so far as finance will allow to create an environment which is as good as anyone these days would expect to work in. The units are warm, well lit, well ventilated and have comfortable rest and relaxation areas. In Unit Five, due to the generosity of Marks \& Spencer who have donated a staff canteen from a store which closed, the facilities are very comfortable indeed and a real incentive to our workers to attend. Economy is rightly a prior concern of planners and funding agencies but it is surely simple logic that a building suited to the purpose, designed with the industrial experience over decades of development, will be in the long run cheaper to maintain, adapt, supervise, and supply energy to, than a building designed for a quite different and incompatible purpose.

\section{Work}

The main product of the workshop is the quality of people's lives and that is the main consideration in deciding the range of work to be undertaken. The work must suit people with a wide range of abilities and aptitudes. It must be varied and produce at the end of the day a sense of satisfaction that something worthwhile has been achieved.

I will not go into great detail about the number of small businesses which we have set up in our workshops but deal only with the social and managerial arrangements. Our aim in each section of our workshops is to produce maximum participation and esprit de corps among the teams of workers. Hence we encourage our supervisors to lead their team of workers in looking for work, devising ways of increasing productivity, designing own products, marketing goods and services and managing their own budgets. The role of senior management is to work with the supervisors to agree goals and targets and to support them in whatever ways they need by introducing appropriate expertise and training.

The key concepts which characterise our approach are flexibility, creativity and opportunism. We try to appoint supervisors who have these qualities in addition to craft or industrial skills. Hence as supervisors change each makes a different contribution to the range of work opportunities on offer.

Two illustrations of this approach are the development of chair caning and rush seating in Cambridge and the sewing section of Unit Five. In each case a highly skilled supervisor has trained workers in craft skills and set up a small business which fills a niche within the locality. One worker in Cambridge has now set up a small seating business of her own and receives support and advice from the workshop.

Material costs are kept down by making maximum use of donations. The bedding, curtains, cushions and small domestic items of sewing produced at Unit Five and sold in the Charity's own shop make extensive use of donations of cloth - end rolls and cloth with slight imperfections from Laura Ashley, Sandersons and other major manufacturers.

\section{Moving on}

For some of our workers moving on to outside employment is not a realistic proposition and for them we are currently looking at alternative sheltered employment projects, which will be the subject of another paper. For the others, however, it has become clear that it is insufficient for someone who is performing well within the workshop simply to be encouraged to look for a job. The process of making the transition from a sheltered environment to open employment is complex and fraught with difficulties. It involves not only the ability to acquire skills and work discipline but also and, perhaps more crucially, it affects the very roots of people's self perception, their ambitions and their confidence in themselves. It therefore became necessary to look at the whole process more carefully and objectively and to devise ways of working with the grain of people's views of themselves while at the same time finding opportunities which would build a string of small successes and minimise the risk of damaging failure. Losing a first job or finding that it does not fulfill expectations can be a shattering experience and can undo all the work of the previous months at the workshop. 
For almost two years now my colleague Anne Aldrich has been engaged on 'action research' to devise ways of assessing the abilities and potential of our workers and of managing the transition to outside employment. This project has been part funded by the MSC as the first Pilot Employment Initiatives for Disabled People.

The task has been in two parts; firstly to devise questionnaires and records which enable the workers to participate in their own assessment over the period of time they are in the workshop. The assessments invite the workers to compare their perceptions of themselves and their skills and abilities with the observations of the supervisors. Thus a dialogue is begun which, if successful, will lead to a more realistic perception by the workers of their employment ambitions, and will also enable staff to understand the sorts of work which the worker finds satisfying and self confirming rather than self negating.

The second part of the task has been to develop a network of local firms who are prepared to take people on work experience placements during which both the worker and the employer receive support in making the placement a success. The time limited nature of these placements minimises the risk of failure and the worker begins to build a pattern of small successes which it is hoped will lead to them acquiring the ability to sustain long-term employment.

During 1987 three firms offered placements and six workers have been able to take advantage of these. One worker has in fact now been taken on as a regular employee of the firm in which she was placed.

\section{Concluding remarks}

Whatever term is used to describe industrial therapy, the employment of people with mental handicap and mental ill health is an essential part of Community Care. If a person does not have the opportunity to make a productive contribution to society within the limits of their capabilities then they are being denied a basic component of human dignity.

A partnership between social welfare agencies and the world of commerce need not herald a return to the workhouse, as long as the cardinal principle is understood that the main purpose of any initiative is to enhance the quality of people's lives.

\title{
Work at Netherne-A service responding to change
}

\author{
MounIR Ekdawi, Consultant Psychiatrist, Netherne Rehabilitation Service, Coulsdon, \\ Surrey
}

Work activities were systematically introduced by R. K. Freudenberg at Netherne Hospital, in the 1950 s, as a component of a rehabilitation programme for severely disabled in-patients. At about the same time, Douglas Bennett utilised the psychological, vocational and economic benefits of work in preparing long-stay Netherne patients for resettlement in the community. The value of work as a principal rehabilitative medium in a wide spectrum of disability was periodically reported. . $^{1,2,3,4}$

Although work rehabilitation is essential to equip some patients for future employment, the view that employment is its ultimate aim is unrealistic, and it can only result in disillusioned patients and demoralised staff. When employment was plentiful in the

Based on a paper given at the College's Spring Quarterly Meeting 1988. 1960s and 1970s, a follow-up study of 367 carefully selected and intensively trained long-stay Netherne patients showed that only about a third could sustain competitive employment. ${ }^{5}$ This ratio has thereafter fluctuated, but it has remained below $50 \%$. Work rehabilitation should therefore not be seen as relevant only to employment problems; the performance of a work role is in itself an indicator of social adjustment, and it is so perceived by those in close contact with the patients. ${ }^{6}$

The number of patients for whom the Netherne Rehabilitation Service are responsible has remained fairly constant at about 300; however, while in 1961 all were long-term in-patients, less than 50 are now in hospital accommodation. During the last 25 years, the impact of social and organisational changes, including the gradual shift to community rehabilitation, the changing scene of the MSC provisions for disabled people and the NHS management reorganisation, have led to various modifications in the 